\#121 Pontos gatilho do complexo crânio-cérvico-mandibular: mesoterapia vs. eletroacupuntura

Filipa Barros dos Santos*, Catarina Aguiar Branco, João Carlos Pinho

Faculdade de Medicina Dentária da Universidade do Porto

Objetivos: Avaliar e comparar a eficácia terapêutica da mesoterapia e eletroacupuntura no tratamento de pontos gatilho faciais e cervicais, através de vários instrumentos aplicados antes e após o tratamento.

Materiais e métodos: A amostra do estudo foi composta por 70 voluntários de ambos os sexos. Numa primeira fase, foi realizada a captação de imagens termográficas, bem como o preenchimento do Research Diagnostic Criteria for Temporomandibular Disorders e da Escala de Qualidade de Vida da Organização Mundial de Saúde. Os voluntários foram divididos aleatoriamente em dois grupos, sujeitos a tratamentos diferentes: mesoterapia ou eletroacupuntura. Após 2 sessões de cada tratamento, foi feita nova captação de imagens termográficas e exame clínico. Os termogramas foram analisados pelo Software FLIR ${ }^{\circledR}$ Tools (FLIR Systems, Wilsonville).

Resultados: Com o teste de Wilcoxon, verificou-se diferenças estatisticamente significativas entre os valores antes e após o tratamento em todas as questões do domínio físico da Escala de Qualidade de Vida da Organização Mundial de Saúde, tanto no grupo da eletroacupuntura como no grupo da mesoterapia, sem predominância em nenhum dos grupos. O mesmo se sucedeu na dor sentida à palpação muscular. O teste Mann-Whitney indica a existência de diferenças estatisticamente significativas na diferença de temperatura entre o momento antes e após a intervenção entre os grupos no masséter esquerdo (corpo), no masséter direito (inserção), no trapézio direito e no occipital esquerdo, cujas médias são superiores no grupo da eletroacupuntura.

Conclusões: Ambos os tratamentos apresentam melhorias significativas na redução da dor à palpação muscular, na qualidade de vida dos participantes e na diferença de temperatura corporal verificada pela termografia. A eletroacupuntura apresenta melhores resultados em tratamentos de fase aguda em músculos que apresentem vários pontos gatilho bem definidos e/ou muito dolorosos e bandas musculares tensas.

http://doi.org/10.24873/j.rpemd.2017.12.144

\section{\#122 Erosão dentária, o consumo alimentar e as bebidas energéticas em atletas}

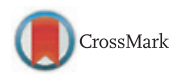

Mohamed-Amine Chetti*, Maria-Raquel G. Silva, Helena Neves, Maria Conceição Manso

Faculdade Ciências da Saúde, FP-ENAS, Universidade Fernando Pessoa, Porto, Portugal

Objetivos: Inúmeros estudos nacionais/internacionais demonstraram a influência da alimentação na cavidade oral, levando à erosão dentária. Sabe-se que os atletas têm um gasto energético importante, portanto, eles precisam adaptar a alimentação de acordo com as suas necessidades energéticas e nutricionais, recorrendo, por vezes, ao consumo de bebidas energéticas. Estas estão, muitas vezes, envolvidas no processo de erosão dentária, devido à sua composição e ao seu pH reduzido. Assim, o objetivo deste estudo é avaliar a relação entre a alimentação, incluindo o consumo de bebidas energéticas com a erosão dentária em atletas.

Materiais e métodos: Estudo com parecer positivo da Comissão de Ética da Universidade. Foi aplicado um questionário sobre os hábitos alimentares, incluindo o consumo de bebidas energéticas a um grupo de atletas ( $\mathrm{n}=110$ : nadadores, culturistas, futebolistas, boxistas, voleibolistas e corredores) repartidos em 4 grupos: nadadores que consumem e que não consomem não bebidas energéticas, e atletas (exceto nadadores) que consumem e que não bebidas energéticas. O grau de erosão dentária de cada atleta foi avaliado através de um exame oral, utilizando o índice BEWE (Basic Erosive Wear Examination). Recorreu-se à análise descritiva e inferencial, usando o programa IBM SPSS Statistics, vs.23, considerando um nível de significância de 0,05.

Resultados: Dos 110 participantes, 48 (43.6\%) indivíduos não apresentaram risco de erosão, 54 (49,1\%) atletas apresentaram baixo risco de erosão, 7 (6.4\%) indivíduos apresentaram um risco médio de erosão, e $1(0,9 \%)$ atleta apresentou alto risco de erosão. Por análise logística multivariável foram identificados como risco para erosão dentária: o consumo de vinho tinto $(O R=1,6 ; p=0,048)$ e de citrinos $(O R=1,3 ; p=0,047)$, o aumento da frequência de escovagem dos dentes $(\mathrm{OR}=2,3$; $\mathrm{p}=0,018$ ), e a prática desportiva, nomeadamente nos atletas que consomem bebidas energéticas $(O R=6,3 ; p=0,003)$, e nadadores que consumem bebidas energéticas $(\mathrm{OR}=15,2$; $\mathrm{p}<0,001)$.

Conclusões: A prática de natação constituiu um factor de risco de erosão dentária nos atletas que consomem bebidas energéticas, o que coloca novos desafios aos Médicos Dentistas, relativamente ao diagnóstico precoce e principalmente à prevenção e tratamento da erosão nestes atletas.

http://doi.org/10.24873/j.rpemd.2017.12.145

\section{\#123 Fatores de insucesso em implantologia}

Carolina Mota*, Catarina Augusto, Bruna Alves, Fatima Bizarra, Helena Francisco, João Caramês

Instituto de implantologia

Objetivos: Identificar os fatores que podem levar ao insucesso da reabilitação implanto-suportada.

Materiais e métodos: A recolha de dados foi feita pela consulta dos processos clínicos de uma amostra de conveniência de pacientes com reabilitação total sobre implantes em maxilares atróficos colocados numa clinica em Lisboa, de janeiro de 2013 a dezembro de 2014 e perdidos até março de 2017. Foi analisado o número total de implantes colocados e perdidos após o período de osteointegração de 6 meses, assim como os meios de higiene oral utilizados pelos pacientes e a frequência de consultas de controlo perimplantar.

Resultados: Resultados: A amostra é composta por 162 indivíduos com uma média de idades de 63,10 $( \pm 1,09)$ anos, 